\title{
Radix Polygalae Extract Attenuates PTSD-like Symptoms in a Mouse Model of Single Prolonged Stress and Conditioned Fear Possibly by Reversing BAG1
}

\author{
Ju-Yeon Shin ${ }^{\dagger}$, Jung-Won Shin ${ }^{\dagger}$, Sang-Kyu Ha, Yoorim Kim, \\ Kelley M. Swanberg, Suck Lee, Tae-Woo Kim and Sungho Maeng* \\ Graduate School of East-West Medical Science, Kyung Hee University, Yongin 17104, Korea
}

\begin{abstract}
Radix Polygalae (RP) has been used to relieve psychological stress in traditional oriental medicine. Recently, cell protective, antiamnestic and antidepressant-like effects were disclosed but the possible application of RP to post-traumatic stress disorder, in which exaggerated fear memory persists, has not yet been explored. For this purpose, the effects of RP on fear behavior was examined in a mouse model of single prolonged stress and conditioned fear (SPS-CF), previously shown to mimic key symptoms of post-traumatic stress disorder. Male mice received daily oral dose of RP extract or vehicle during the SPS-CF procedure. Then fear-related memory (cohort 1, n=25), non-fear-related memory (cohort 2, n=38) and concentration-dependent effects of RP on fear memory (cohort 3, $\mathrm{n}=41$ ) were measured in 3 separate cohort of animals. Also working memory and anxiety-like behaviors were measured in cohort 1. RP-treated SPS-CF mice exhibited attenuated contextual but not cued freezing and no impairments in the working memory and spatial reference memory performances relative to vehicle-treated SPS-CF controls. RP-treated SPS-CF and naive mice also demonstrated no difference in anxiety-like behavior levels relative to vehicle-treated SPS-CF and naive controls, respectively. In the hippocampus of SPS-CF mice, expression of BAG1, which regulates the activity of GR, was decreased, whereas RP increased expression of BAG1 in naïve and SPS-CF mice. These results suggest that RP exerts some symptomatic relief in a mouse with exaggerated fear response. RP and its molecular components may thus constitute valuable research targets in the development of novel therapeutics for stress-related psychological disorders.
\end{abstract}

Key words: Yuan zhi, fear, PTSD, traumatic stress disorders, anxiety

\section{INTRODUCTION}

Received April 12, 2018, Revised May 4,2018,

Accepted May 7, 2018

\footnotetext{
* To whom correspondence should be addressed.

TEL: 82-31-201-2916, FAX: 82-31-204-8119

e-mail: jethrot@hotmail.com

These authors contributed equally.
}

Radix Polygalae (RP), the dried root of Polygalae tenuifolia Willd, has traditionally been used across East Asia in a number of capacities, including an expectorant, memory enhancer and sleep aid [1]. In preclinical research, RP and extract fractions have demonstrated neuroprotective, nootropic [2], and antidepressant-like properties [3]. Constituents of RP have also attenuated behavioral altera- 
tions induced by chronic unpredictable stress and corticotrophinreleasing hormone injection [4]. As both experimental evidence and traditional understanding thus suggest that RP may aid the development of therapeutics for anxiety disorders, we decided to test the effects of its extract in single prolonged stress-conditioned fear (SPS-CF) mouse model, which recapitulates key symptoms of post-traumatic stress disorder (PTSD).

PTSD is a condition of chronic abnormal emotional response to past traumatic experiences [5]. While sympathetic hyper-reactivity triggered by cues of fear memory are adaptive that ensures an organism's avoidance of repeated danger, when such hyperarousal is triggered chronically and cause debilitating symptoms, PTSD may be diagnosed [6]. FDA approved sertraline and paroxetine have been reported with low remission, frequent relapse, and treatmentrefractory symptoms [7]. Thus the development of novel pharmacological therapies for PTSD are in high priority.

A large body of evidence supports validity of the single prolonged stress (SPS) paradigm as a rodent model of PTSD [8]. While SPS in rats was described with recurrent fear response to environmental cues and low serum glucocorticoid levels suggestive of PTSD-like hypothalamus-pituitary-adrenal axis suppression, electrical foot shock (EFS) training prior to SPS application was required to establish comparably stable responses in mice [9]. This modified protocol provided improved validity to PTSD compared with either SPS or conditioned fear alone [9].

$\mathrm{Bcl}$-2-associated athanogene (BAG1) is a regulatory cochaperone that attenuated the glucocorticoid receptor (GR) nuclear trafficking and functions. Due to the finding that BAG1 overexpressed mice under the NSE (neuron-specific enolase) promotor showed an increased resistance to stress [10], and antagonizing the effect of GR improved the symptoms of treatment-resistant PTSD [11], we investigated whether RP administration increases the expression of BAG1 in SPS-CF model mice. Therefore, in order to examine the possible utility of RP in further development of novel pharmaceutical therapies for PTSD, we tested the pharmacological effect of RP extract on mice exposed to SPS-CF.

\section{MATERIALS AND METHODS}

\section{Animals}

Seven-week old male C57Bl/6 mice (Central Laboratory Animals Inc., Korea) $(\mathrm{n}=104)$ were housed in a temperature- and humidity- controlled environment under 12-hour light-dark cycles (7:00 AM to 7:00 PM) with free access to chow and water.

All protocols were approved by the Institutional Animal Care and Use Community of Kyung Hee University (KHMC-IACUC: 12-009) and thus conducted in accordance with the NIH Guide for the Care and Use of Laboratory Animals. All tests were conducted between the hours of 9:00 and 18:00.

\section{Preparation of RP extract}

RP was purchased from Kyung Hee Hanyak (Korea). A voucher specimen was deposited. Dried RP was boiled at $80^{\circ} \mathrm{C}$ in $70 \%$ ethanol for 1 hour then repeated for 40 more minutes. The combined filtrate was evaporated on a rotary evaporator under reduced pressure and freeze-dried to yield $28 \%(\mathrm{w} / \mathrm{w})$ of the original product. For experimental use, crude extracts were completely dissolved in DW at a concentration of $10 \mu \mathrm{g} / \mathrm{ml}(\mathrm{w} / \mathrm{v})$.

\section{SPS-CF stress exposure}

SPS-CF was adapted from a method previously described [9]. Briefly, training consisted of daily EFS delivery for 5 days. Sessions began with $60 \mathrm{~s}$ of chamber adaptation (JD-SI-11 Shuttle Box, Jeungdo B\&P), followed by $10 \mathrm{~s}$ of $80 \mathrm{~dB}$ white noise cue and chamber illumination. An EFS of $1 \mathrm{~mA}$ was delivered during the last $2 \mathrm{~s}$ of cue signals. On the sixth day, mice suffered SPS by 2 hours of immobilization, 20 minutes of forced swimming and exposure to ether until the loss of consciousness. For the next 7 days, mice were left undisturbed in their home cages.

\section{Conditioned fear test}

Freezing following exposure to the shock chamber and white noise were observed as measurements of acquired fear for context and cue, respectively. Contextual freezing was measured in the shock chamber for 5 minutes. For the measurement of cued freezing, mice were placed in a novel chamber shaped like an equilateral triangular prism (base length $24 \mathrm{~cm}$; height $57 \mathrm{~cm}$; height 35 $\mathrm{cm}$ ) for 3 minutes, followed by 3 minutes of the $80 \mathrm{~dB}$ white noise. Activity was videotaped for later analysis.

\section{Ymaze}

Y maze consisted with three corridors joined at the center at equal angles. Alternation was defined as a sequential visit to each arm without repetition of either of the two previous arms. After placing a mouse in the maze, movements were recorded for 5 minutes. Percent alternation was calculated as the number of correct alternations per total arm visits minus 2 [12].

\section{Open field test}

Spontaneous locomotion was measured in a plexiglass box in a dimly lit room. Locomotor activity of the mice placed in the box was traced for 30 minutes. Distance moved in the open field was analyzed with Smart 3.0 videotracking software (Panlab, Spain). 


\section{Elevated plus maze}

Anxiety-like behaviors was measured by the elevated plus maze. The apparatus was a cross-shaped maze which has open arms and closed arms on each side, which were elevated $60 \mathrm{~cm}$ above the floor. For test, mice were placed in the center region with its head pointing toward an open arm. The movement of mice through the maze was recorded for 5 minutes. Time spent in open arms was analyzed using Smart software.

\section{Novelty-suppressed feeding test}

The novelty-suppressed feeding test compares the strength of a mouse's fear for open environments against its desire to feed; our version of the test was adapted from a method previously described [13]. Before testing, mice were deprived of food in the home cage for 24 hours. During testing, a food pellet was placed in the center of the test box, and a mouse was lowered to a corner of the box. The latency until the mouse bit the pellet was measured for 10 minutes. Any sniffing or touching the pellet was ignored. If the mouse had not acquired the pellet within 10 minutes, feeding latency was recorded as 10 minutes. After this, mice were returned to their home cages, and the latency to acquire a food pellet was observed.

\section{Morris water maze}

Long-term spatial memory was measured by performance on the Morris water maze. Testing was performed in a water tank (80 $\mathrm{cm}$ diameter) filled to $0.5 \mathrm{~cm}$ above a platform with tap water made opaque by white paint. For 5 days, mice were trained to locate the submerged platform according to symbols placed around the walls. Each training day included 4 sessions, each starting in a different quadrant. Mice were given 60 seconds to locate the platform, and were allowed to remain on it for $10 \mathrm{~s}$ before being returned to the home cage. If mouse was unable to escape within 60 seconds, it was guided to the platform. On the sixth day, probe test was performed without the platform, during which the time spent in the target quadrant was measured for 60 seconds.

\section{Western blot}

For tissue collection, mice were deep anesthetized, decapitated and each hippocampus was rapidly dissected and stored at $-80^{\circ} \mathrm{C}$ until use. Immunoblotting was performed as described previously [3]. In brief, the hippocampus was denatured in lysis buffer and the protein concentration was determined by BCA method (Bio-rad, CA, USA). Then it was resolved by SDS-PAGE and transferred to the PVDF membrane. Primary antibodies (anti-BAG1; sc-377454, anti-beta actin; sc-517582, Santa Cruz Biotech. Dallas TX) were diluted to a 1:1000 concentration ratio and applied overnight at $4^{\circ} \mathrm{C}$.
After an hour of incubation in 1:1000 diluted secondary antibody, bands were visualized by ECL solution (Thermo Fisher Scientific, MA) and quantified with a chemiluminiscence detector (Davinch Chemi imaging system, CellTagen, Korea) and the ImageJ image analysis software (NIH, USA).

\section{HPLC analysis}

Norharmane (P1121) and 3,4,5-trimethoxycinnamic acid (TMCA, T1104) were purchased from TCI (Japan). Tenuifolin (CFN98157) and 3,6,disinapoyl sucrose (DISS; CFN90578) were purchased from ChemFaces (Wuhan, China). The HPLC analysis was performed on an Agilent 1100 series liquid chromatograph with diode array detector (DAD) interfaced with an Agilent Chem. Station for the data analysis. The column was a $4.6 \mathrm{~mm}$ ID $\times 250$ mm Zorbax Eclipse Plus C18 column ( $5 \mu \mathrm{m}$ pore size; Agilent, CA) with a Security GuardTM guard cartridge $(3.0 \times 4.0 \mathrm{~mm}$, Phenomenex, CA). The mobile phase was composed of $0.1 \%$ phosphoric acid in water and acetonitrile using the following linear gradient program: 0 20 min, 10 40\% ; 20 30 min, 40 50\%. Chromatography was carried out in gradient mode using a flow rate of $1.2 \mathrm{ml} / \mathrm{min}$ at $25^{\circ} \mathrm{C}$ and was detected at various UV wavelength of individual standards and polygalae radix sample. Injection volume is $10 \mu \mathrm{L}$. The stock solutions of norharmane, DISS, and TMCA were prepared at $0.1 \mathrm{mM}$ in DMSO $(16.8,75.5,23.816 .8 \mu \mathrm{g} / \mathrm{ml}$, respectively). The stock solution of tenuifolin was prepated at 1 $\mathrm{mM}$ in DMSO $(680.4 \mu \mathrm{g} / \mathrm{ml})$. Polygalae radix extract powder was dissolved in DMSO at $20 \mathrm{mg} / \mathrm{ml}$.

\section{Statistical analysis}

SPSS ver. 20 was used for statistical analysis. Between-group comparisons were made using one- and two-way ANOVA. Tukey's HSD test was performed following significant results. Alpha was set at $\mathrm{p}<0.05$.

\section{RESULTS}

\section{Outline of experimental procedures}

After a week of habituation, mice in the cohort 1 and 2 were assigned to four groups: 1) vehicle + non-stress (VeN); 2) RP $0.1 \mathrm{mg} /$ $\mathrm{kg}+$ non-stress (RPN); 3) vehicle + SPS-CF (VeS); 4) RP $0.1 \mathrm{mg} / \mathrm{kg}$ + SPS-CF (RPS). In cohort 3, mice were assigned to five groups: 1 ) vehicle + SPS-CF (RPS0); 2) RP $0.1 \mathrm{mg} / \mathrm{kg}+$ SPS-CF (RPSO.1); 3) $\mathrm{RP} 1 \mathrm{mg} / \mathrm{kg}+$ SPS-CF (RPS1); 4) RP $10 \mathrm{mg} / \mathrm{kg}+$ SPS-CF (RPS10); 5) $\mathrm{RP} 100 \mathrm{mg} / \mathrm{kg}+\mathrm{SPS}-\mathrm{CF}$ (RPS100). RP was administered by oral gavage during the SPS-CF exposure and undisturbed period for total 13 days. Vehicle group was fed the same volume of DW. All behavioral procedures started at day 14 (Fig. 1). 


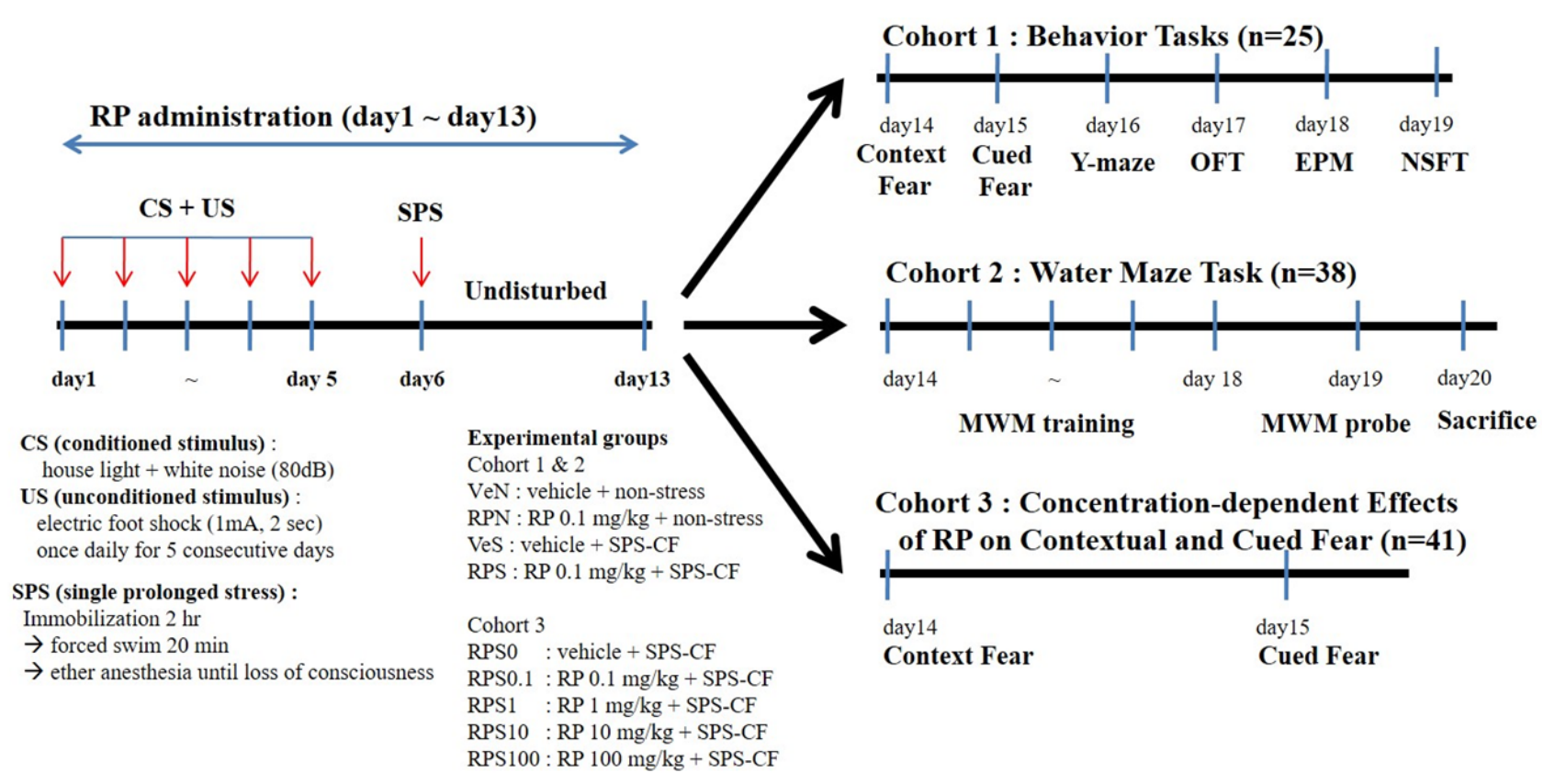

Fig. 1. Schematic diagram of behavioral procedures. Eight weeks old male C57Bl/ 6 mice were used in 3 separate cohorts. SPS-CF was exposed by 5 days of electric shock ( $1 \mathrm{~mA}, 2 \mathrm{sec})$ combined with white noise ( $80 \mathrm{~dB})$ and light illumination, followed by immobilization ( $2 \mathrm{hr})$, forced swim (20 min), and ether anesthesia in the $6^{\text {th }}$ day. Then mice were left undisturbed for 7 days. In cohortl, contextual and cued freezing, alternation in the Y-maze, locomotion in the open field and anxiety levels in the elevated plus maze and novelty suppressed feeding test was measured. In cohort 2, spatial reference memory was measured in the Morris water maze. Then mice were sacrifice for tissue collection. In cohort 3, concentration-dependent effects of RP on contextual and cued fear was measured.

\section{$R P$ reduces conditioned fear to context but not auditory cue in SPS-CF mice}

Fear memory was measured by the intensity of freezing to context and auditory cue (Fig. 2). By exposure to the context, freezing response was higher in SPS-CF mice than unstressed mice both after vehicle (VeN vs VeS, $\mathrm{p}<0.001$ ) and RP (RPN vs RPS, $\mathrm{p}<0.001$ ) treatment (Fig. 2A). Among SPS-CF mice, freezing time was lower in RP-treated relative to vehicle-treated (VeS vs RPS, $\mathrm{p}<0.01$ ). The freezing response to context exposure was lower in all dose ranges $[0.1 \mathrm{mg} / \mathrm{kg}(\mathrm{p}=0.004), 1 \mathrm{mg} / \mathrm{kg}(\mathrm{p}=0.011), 10 \mathrm{mg} / \mathrm{kg}(\mathrm{p}<0.001)$ and $100 \mathrm{mg} / \mathrm{kg}(\mathrm{p}=0.002)]$ relative to untreated (Fig. 2B).

Freezing response to auditory cue demonstrated a significant effect of SPS-CF before and after the presentation of auditory cue $(\mathrm{p}<0.001)$, but RP had no effect on cue-induced fear reduction in SPS-CF mice (VeS vs RPS, p=0.55) (Fig. 2C). Freezing response to auditory cue after incremental doses of RP was non-significant ( $\mathrm{p}=0.61$ ) (Fig. 2D). These results showed a selective effect of RP on contextual conditioned fear reduction but not on cue-induced conditioned fear in SPS-CF mice.

\section{Spatial reference and working memories were improved or maintained by RP in SPS-CF mice}

Because the reduction of contextual fear response by RP could be a consequence of cognitive impairments, spatial reference and working memory was measured in the Morris water maze and Ymaze, respectively (Fig. 3).

The latency to locate the hidden platform in Morris water maze was delayed by SPS-CF (VeN vs VeS, p<0.001) (Fig. 3A). RP improved the latency in SPS-CF mice (VeS vs RPS, $\mathrm{p}<0.001$ ). On the probe trial in Morris water maze, SPS-CF mice spent less time in the target quadrant than unstressed mice whether in RP- (VeN vs VeS, $\mathrm{p}<0.05$ ) or RP+ (RPN vs RPS, $\mathrm{p}<0.01)$ conditions (Fig. 3B). $\mathrm{RP}$ had no effect on time spent in the target quadrant relative to unstressed (VeN vs RPN, $\mathrm{p}=0.593$ ) or SPS-CF mice (VeN vs RPS, $\mathrm{p}=0.895)$. Percent alternation in the Y-maze, as a measurement of working memory, demonstrated no effect by SPS-CF $(\mathrm{p}=0.42)$ and $\mathrm{RP}(\mathrm{p}=0.84)$ treatment (Fig. 3C). There was no difference in the swimming speed among experimental groups.

Because the performance in Morris water maze and Y-maze depends on activities in the maze, spontaneous locomotion was measured in the open field. SPS-CF and RP had no effect on travel distance, which meant our cognitive measurement was not confounded by activity changes (Fig. 3D). Based on these findings, RP's reduced contextual fear memory without disrupting spatial reference and working memories. 

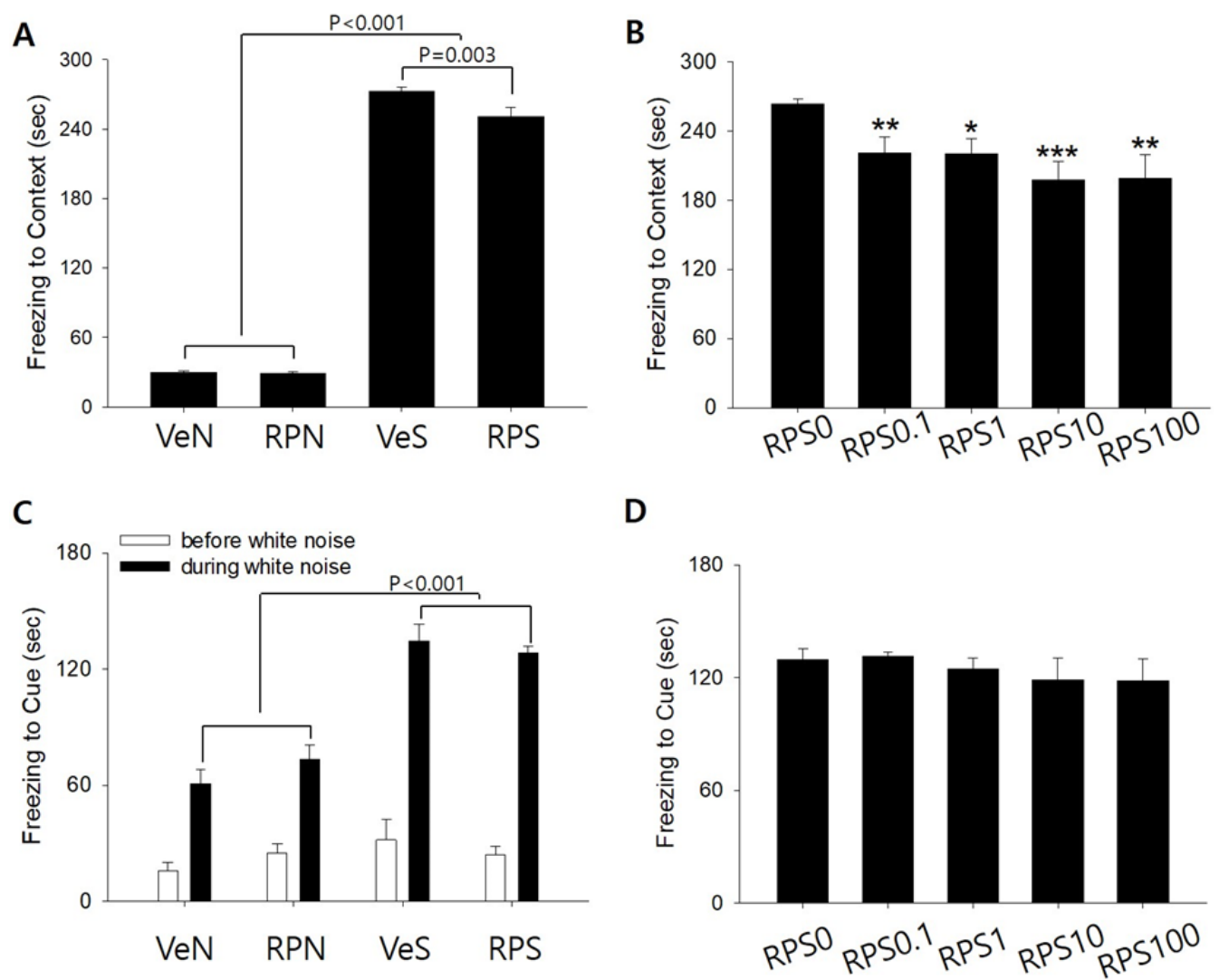

Fig. 2. Effects of RP extract on SPS-CF stress-induced increased fear memory. (A) Conditioned fear response to context exposure ( $\mathrm{n}=6$ for VeN, RPN, VeS, $\mathrm{n}=7$ for RPS). Two-way ANOVA demonstrated a significant effect of SPS-CF $\left(F_{1,21}=2779.0, \mathrm{p}<0.001\right)$ and $\mathrm{RP}\left(F_{1,21}=6.2\right.$, $\left.\mathrm{p}=0.022\right)$ on the freezing time. Also a significant SPS-CF $\times$ RP $\left(F_{1,21}=5.8, \mathrm{p}=0.026\right)$ existed. RP reduced freezing in SPS-CF mice (VeS vs RPS: $\mathrm{p}=0.003$, Tukey's HSD post-hoc test). (B) Concentration-dependent effects of RP on contextual freezing $(\mathrm{n}=41)$. Univariate ANOVA showed a significant effect of RP doses $\left(F_{4,36}=5.5\right.$, $\mathrm{p}<0.001)$; Tukey's HSD post-hoc test confirmed that the intensity of freezing in $0.1 \mathrm{mg} / \mathrm{kg}(\mathrm{p}=0.004), 1 \mathrm{mg} / \mathrm{kg}(\mathrm{p}=0.011), 10 \mathrm{mg} / \mathrm{kg}(\mathrm{p}<0.001)$ and 100 $\mathrm{mg} / \mathrm{kg}(\mathrm{p}=0.002)$ dosed mice was reduced. ${ }^{*} \mathrm{p}<0.05,{ }^{* *} \mathrm{p}<0.01,{ }^{* *} \mathrm{p}<0.001$ vs RPS0. (C) Conditioned fear response to the presentation of auditory cue $(\mathrm{n}=24)$. Three-way ANOVA demonstrated a significant effect of SPS-CF $\left(F_{1,40}=52.3, \mathrm{p}<0.001\right)$, and the presence of auditory cue $\left(F_{1,40}=228.4, \mathrm{p}<0.001\right)$, but RP administration had no effect $\left(F_{1,40}=0.16, \mathrm{p}=0.69\right)$. Interaction between SPS-CF $\times$ auditory cue was significant $\left(F_{1,40}=32.5, \mathrm{p}<0.001\right)$. (D) Concentration-dependent effects of RP on cue-induced freezing $(n=41)$. The intensity of freezing was not changed by any of the RP doses in SPS-CF mice (ANOVA; $F_{4,36}=0.68, \mathrm{p}=0.61$ ). All data represent mean $\pm \mathrm{SEM}$. VeN, vehicle fed, non-stressed; RPN, $R P 0.1 \mathrm{mg} / \mathrm{kg}$ fed, non-stressed; VeS, vehicle fed, SPSCF exposed; RPS, RP $0.1 \mathrm{mg} / \mathrm{kg}$ fed, SPS-CF exposed; RPS0, vehicle fed, SPS-CF exposed; RPS0.1, RP $0.1 \mathrm{mg} / \mathrm{kg}$ fed, SPS-CF exposed; RPS1, RP $1 \mathrm{mg} / \mathrm{kg}$ fed, SPS-CF exposed; RPS10, RP $10 \mathrm{mg} / \mathrm{kg}$ fed, SPS-CF exposed; RPS100, $R P 100 \mathrm{mg} / \mathrm{kg}$ fed, SPS-CF exposed.

\section{Anxiety-like behaviors were not changed by RP treatment}

Because the reduction of contextual fear response by RP could be a consequence of anxiolytic effect, anxiety-like behaviors were measured in the elevated plus maze and novelty suppressed feeding paradigm (Fig. 4).

Both SPS-CF and RP treatment had no effect on open arms time in the elevated plus maze (Fig. 4A). Similarly, the latency to feed in novelty suppressed feeding paradigm were non-significant (Fig. $4 \mathrm{~B})$. In their homecages, which is a familiar environment, all mice acquired a food pellet within 5 seconds. Based on these findings, reduced contextual fear was not a consequence of anxiolytic effect.

\section{Increased hippocampal BAG1 expression by RP treatment}

The expression of BAG1 was measured in the SPS-CF and RP treated mice (Fig. 5). BAG1 is a regulatory protein of GR which has the role of increasing stress resistance. Compared with unstressed mice, the hippocampal BAG1 expression was reduced in SPS-CF mice (VeN vs VeS, $\mathrm{p}=0.027$ ). Compared with SPS-CF mice, RP treatment to SPS-CF mice increased the hippocampal BAG1 expression (VeS vs RPS, $\mathrm{p}=0.045$ ).

\section{HPLC detection of RP key components}

The presence of norharmane, DISS, TMCA, and tenuifolin, which are the known key components of RP extract, was tested using the HPLC analysis. To measure the retention time, $10 \mu \mathrm{l}$ of 
A

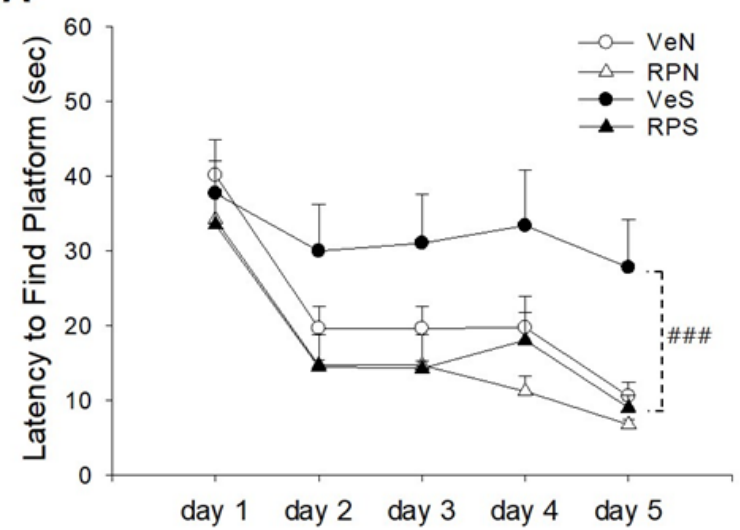

C

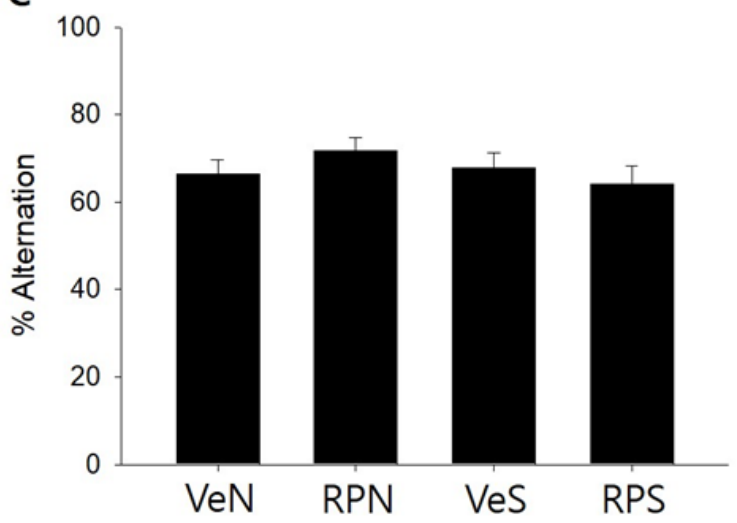

B

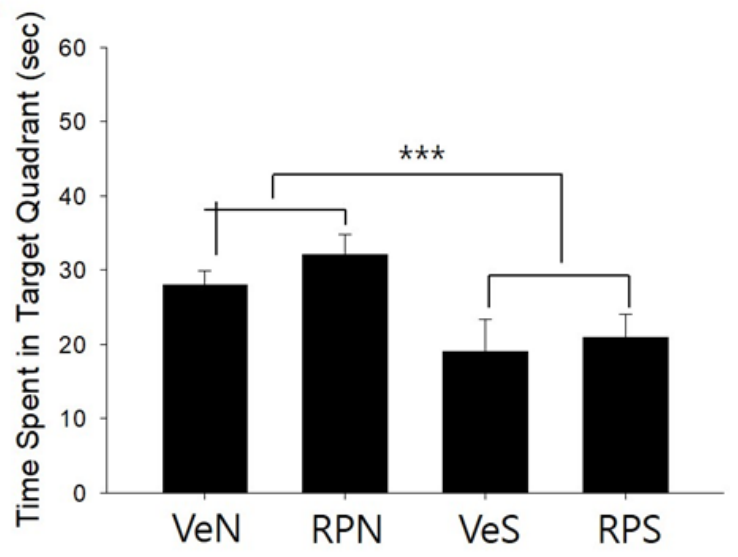

D

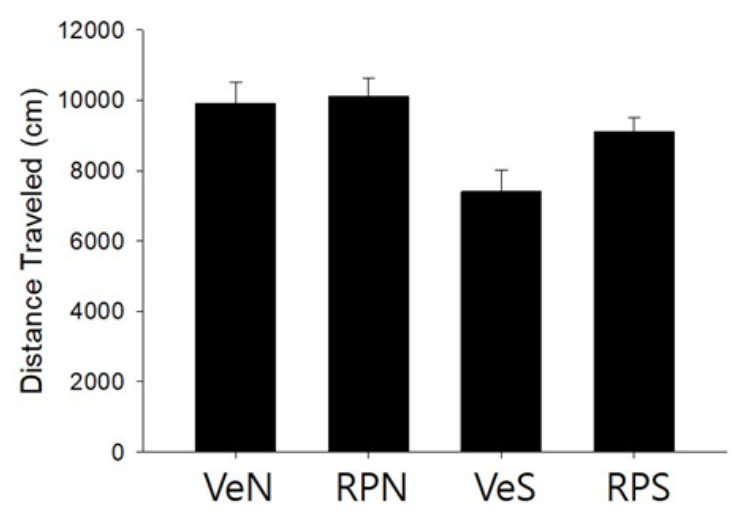

Fig. 3. Effects of RP on SPS-CF stress-induced memory impairment of spatial memory. (A) Latency to find hidden platform in Morris water maze during 5 daily training sessions ( $\mathrm{n}=9$ for VeN and RPN, $\mathrm{n}=10$ for VeS and RPS). Three-way ANOVA demonstrated a significant effect by daily repetition of training $\left(F_{4,170}=15.9, \mathrm{p}<0.001\right)$, SPS-CF exposed stress $\left(F_{1,170}=9.2, \mathrm{p}=0.003\right)$, and RP administration $\left(F_{1,170}=26.8, \mathrm{p}<0.001\right)$. Only stress $\times$ RP administration showed a significant interaction $\left(F_{1,170}=4.9, \mathrm{p}=0.028\right)$. Post-hoc multiple comparison showed a significant effect of RP on reducing the latency in SPS-CF $(\mathrm{p}<0.001)$. (B) Time spent in the target quadrant during the probe trial of Morris water maze test $(\mathrm{n}=38)$. Two-way ANOVA demonstrated a significant effect of SPS-CF exposure $\left(F_{1,34}=32.5, \mathrm{p}<0.001\right)$, but not of RP administration $\left(F_{1,34}=2.9, \mathrm{p}=0.097\right)$ and SPS-CF exposure $\times$ RP interaction $\left(F_{1,34}=0.4\right.$, $\mathrm{p}=0.53$ ). (C) Working memory performance in the in the Y maze. Two-way ANOVA demonstrated no significant effect neither by SPS-CF exposure $\left(F_{1,21}=0.68, \mathrm{p}=0.42\right)$, RP administration $\left(F_{1,21}=0.04, \mathrm{p}=0.84\right)$ and SPS-CF $\times$ RP interaction $\left(F_{1,21}=1.7, \mathrm{p}=0.21\right)$ in \% alternation. (D) Spontaneous locomotion in the open field during 30 minutes. Two-way ANOVA demonstrated no significant effect either by SPS-CF stress $\left(F_{1,21}=3.75\right.$, p $\left.=0.11\right)$, RP administration $\left(F_{1,21}=0.6, \mathrm{p}=0.45\right)$ and SPS-CF $\times$ RP interaction $\left(F_{1,21}=0.86, \mathrm{p}=0.37\right)$ in the total distance traveled. All data represent mean \pm SEM. VeN, vehicle fed, non-stressed; RPN, RP $0.1 \mathrm{mg} / \mathrm{kg}$ fed, non-stressed; VeS, vehicle fed, SPS-CF exposed; RPS, RP $0.1 \mathrm{mg} / \mathrm{kg}$ fed, SPS-CF exposed. ${ }^{* * *} \mathrm{p}<0.001$; non-stressed vs SPS-CF exposed. ${ }^{\# \#} \mathrm{p}<0.001$; VeS vs RPS.

the stock solution of each molecules were injected. The retention time of norharmane, DISS, TMCA and tenuifolin was 8.613 minute measured at $254 \mathrm{~nm}, 13.15$ minute measured at $330 \mathrm{~nm}, 18.68$ minutes measured at $310 \mathrm{~nm}$ and 21.38 minute measured at 202 $\mathrm{nm}$, respectively. In the RP extract, peaks of norharmane (Fig. 6A), DISS (Fig. 6B), TMCA (Fig. 6C) were identified. But the peak of tenuifolin (Fig. 6D) was not detected.

\section{DISCUSSION}

PTSD is characterized by repetitive episodes of heightened anxiety and fear reactions of victims who have previously been exposed to psychological trauma. Cognitive treatments and pharmacological agents that attempt to treat this disorder have limited efficacy. Here we provide evidence that RP extract can specifically reduce conditional fear memory without interfering with spatial reference or working memory.

SPS-CF is a mouse model that shares many characteristics with PTSD [9]. In a previous study, mice exposed to SPS-CF showed excessive conditional fear, deficit in novel object memory, and apoptotic cell death in the hippocampus [9]. In our study, SPS-CF mice showed more fear responses to conditioned context and auditory 
A

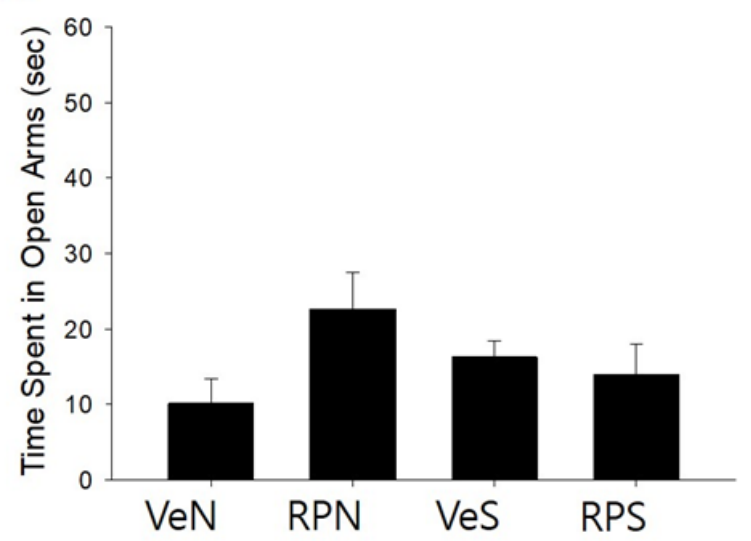

B

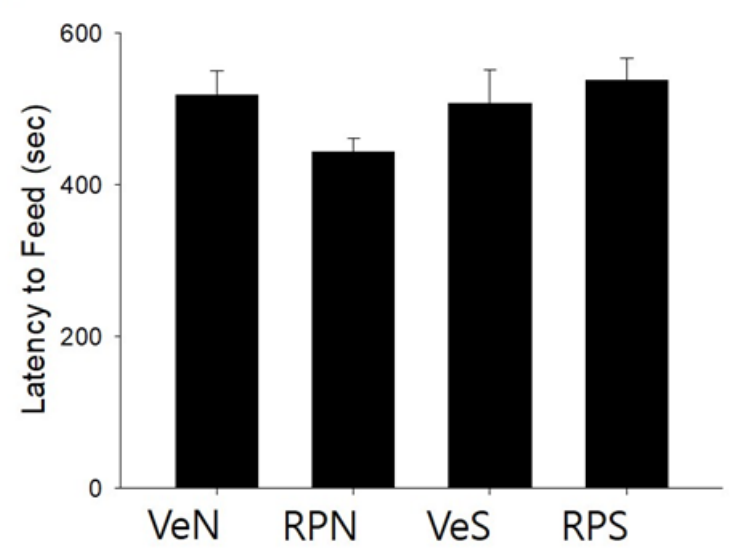

Fig. 4. Effects of RP on anxiety-like behaviors in SPS-CF exposed mice. (A) Time spent in open arms in the elevated plus maze ( $\mathrm{n}=6$ for VeN, RPN, VeS, $\mathrm{n}=7$ for RPS). Two-way ANOVA demonstrated non-significant changes by SPS-CF exposed stress $\left(F_{1,21}=0.96, \mathrm{p}=0.76\right)$, and RP administration $\left(F_{1,21}=1.7\right.$, $\mathrm{p}=0.21)$. Also there were no significant stress $\times \mathrm{RP}$ administration interaction $\left(F_{1,21}=3.6, \mathrm{p}=0.071\right)$. (B) Latency to feed in the novelty suppressed feeding paradigm. Two-way ANOVA demonstrated non-significant changes by SPS-CF exposed stress $\left(F_{1,21}=1.8, \mathrm{p}=0.195\right)$, RP administration $\left(F_{1,21}=0.52\right.$, $\mathrm{p}=0.48)$ and SPS-CF $\times$ RP interaction $\left(F_{1,21}=2.9, \mathrm{p}=0.104\right)$. All data represent mean $\pm \mathrm{SEM}$. VeN, vehicle fed, non-stressed; RPN, $R P 0.1 \mathrm{mg} / \mathrm{kg}$ fed, nonstressed; VeS, vehicle fed, SPS-CF exposed; RPS, RP $0.1 \mathrm{mg} / \mathrm{kg}$ fed, SPS-CF exposed.

A

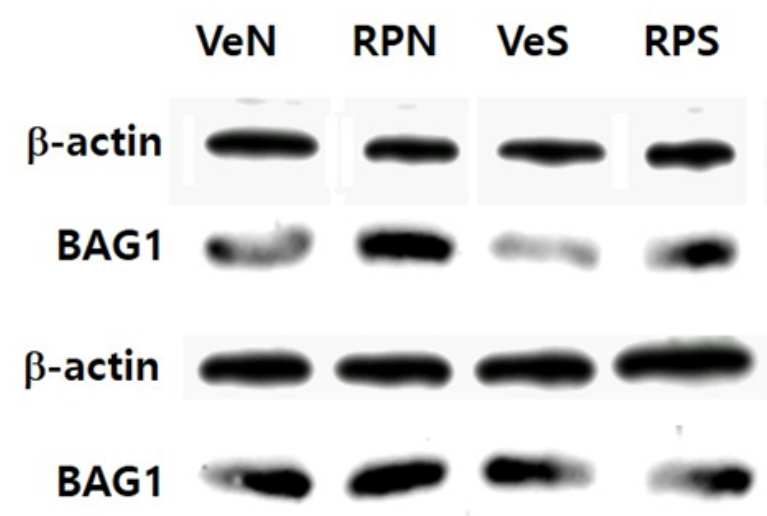

B

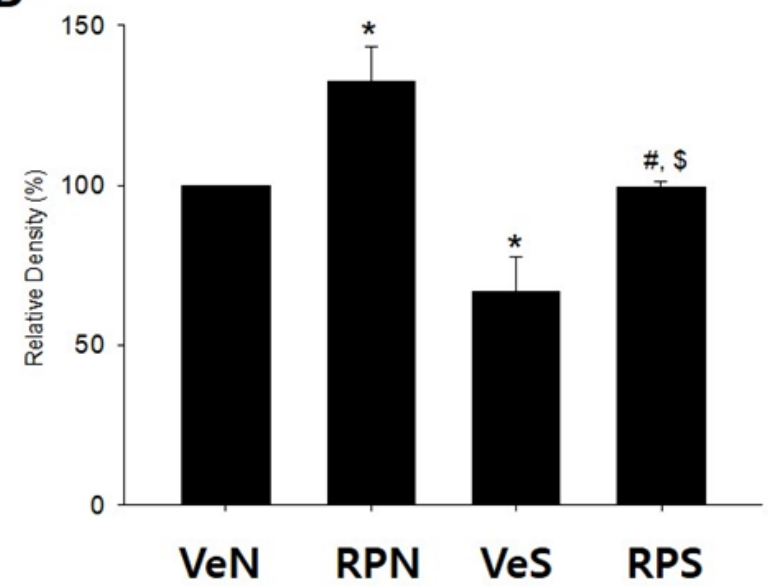

Fig. 5. The effect of Radix Polygalae on hippocampal BAG1 expression ( $\mathrm{n}=4$ for each group). (A) Representative western blot images. (B) Bar graph of western blot densitometry. ANOVA revealed significant group difference $[\mathrm{F}(3,15)=11.7, \mathrm{p}=0.001]$. Compared with unstressed mice, SPS-CF mice showed reduction of hippocampal BAG1 expression in both mice treated with vehicle (VeN vs VeS, $p=0.027$ ) and RP (RPN vs RPS, $p=0.032$ ). Mice treated with RP demonstrated higher BAG1 expression both in unstressed (VeN vs RPN, $\mathrm{p}=0.049$ ) and SPS-CF (VeS vs RPS, p=0.045). All data values represents mean \pm SEM. VeN, vehicle fed, non-stressed; RPN, $R P 0.1 \mathrm{mg} / \mathrm{kg}$ fed, nonstressed; VeS, vehicle fed, SPS-CF exposed; RPS, $R P 0.1 \mathrm{mg} / \mathrm{kg}$ fed, SPS-CF exposed. ${ }^{*} \mathrm{p}<0.05$ vs VeN. ${ }^{*} \mathrm{p}<0.05$ vs RPN. ${ }^{\$} \mathrm{p}<0.05$ vs VeS. ANOVA, Tukey's HSD post-hoc test.

signals compared to unstressed controls. In the Morris water maze test, SPS-CF mice spent more time finding the escape platform during the acquisition trials and spent less time in the target quadrant during the retention test. In the unstressed mice, 13-day RP administration did not affect the fear response. However, in SPSCF mice RP decreased context-induced fear, but did not affect cue-induced fear. The reduction of this fear response was not due to the lack of contextual memory because the working memory and spatial memory were not affected, but rather improved. This is consistent with previous findings that RP prevented the spatial memory impairment in scopolamine-treated rats [2] and that RP components showed improvement in hippocampus-dependent learning and age-related memory loss [14].

Increased spontaneous locomotion activities can be misinterpreted as an improved memory in the Morris water maze and Ymaze task, as well as a reduced fear memory in conditioned fear 
A

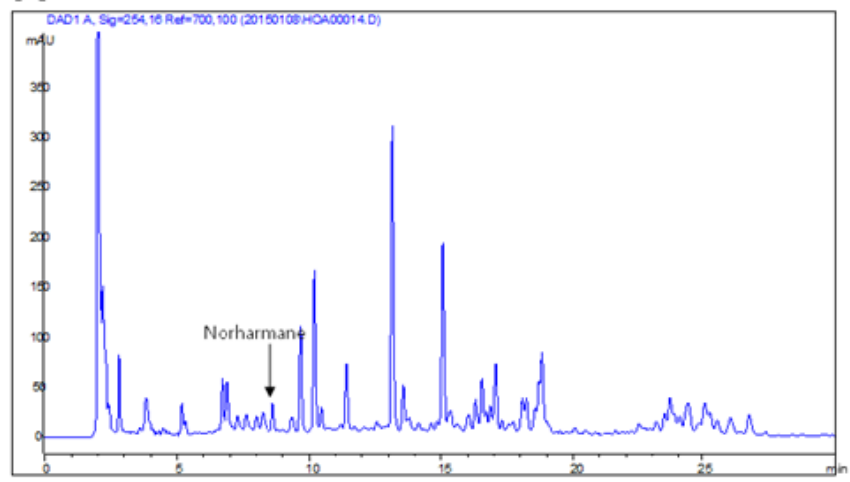

C

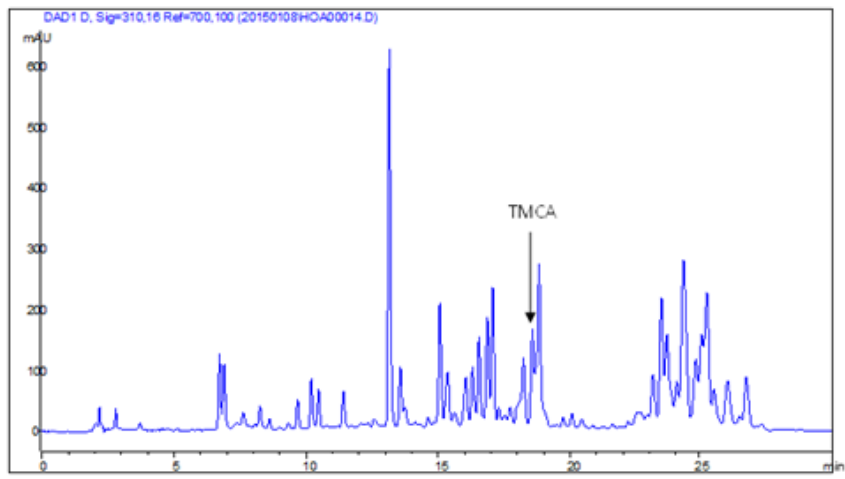

B

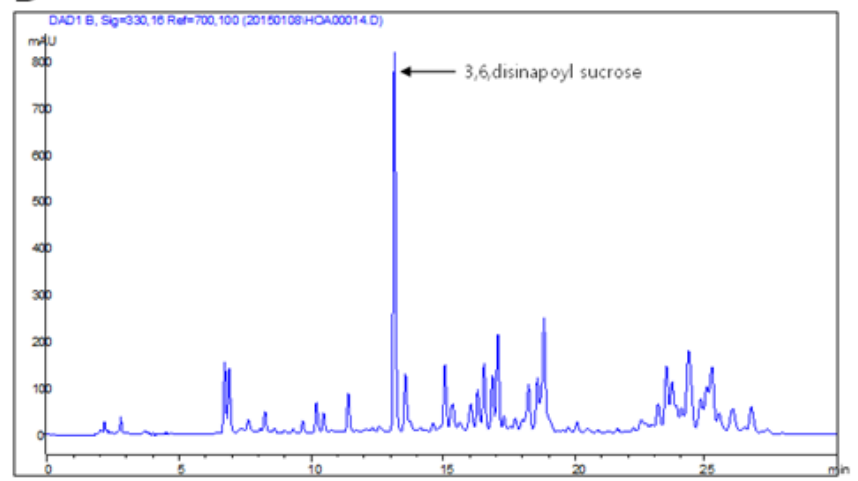

D

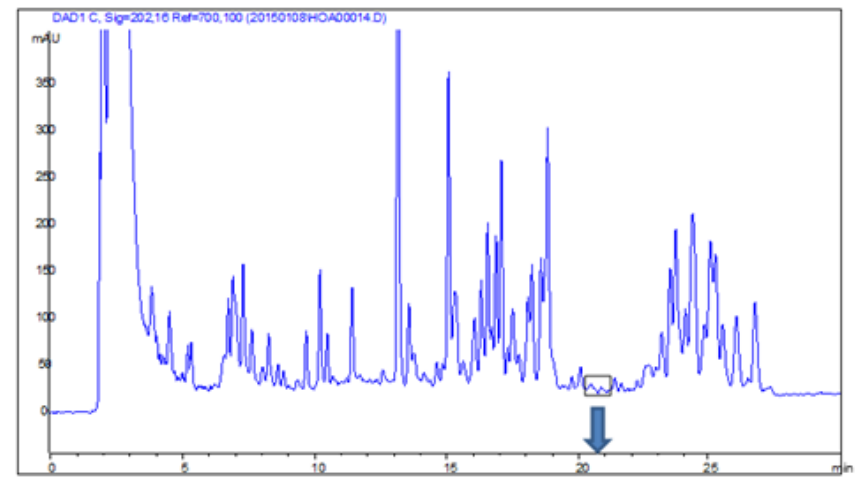

Fig. 6. HPLC analysis of RP key components. The HPLC analysis was performed on an Agilent 1100 series liquid chromatograph with diode array detector interfaced with an Agilent Chem. Station for the data analysis. The column was a $4.6 \mathrm{~mm}$ ID $\times 250 \mathrm{~mm}$ Zorbax Eclipse Plus C18 column (5 $\mu \mathrm{m}$ pore size; Agilent, CA) with a Security GuardTM guard cartridge $(3.0 \times 4.0 \mathrm{~mm}$, Phenomenex, CA). The mobile phase was composed of $0.1 \%$ phosphoric acid in water (a) and acetonitrile (b) using the following linear gradient program: 0 20 min, 10 40\% B; 20 30 min, 40 50\% B. Chromatography was carried out in gradient mode using a flow rate of $1.2 \mathrm{ml} / \mathrm{min}$ at $25^{\circ} \mathrm{C}$ and was detected at various UV wavelength of individual standards and polygalae radix sample. Four standards (Norharmane, TMCA, DISS, Tenuifolin) were prepared at 16.8, 23.8, 75.5, 680.4 $\mu \mathrm{g} / \mathrm{ml}$, respectively. Polygalae radix extract powder was dissolved in DMSO at $20 \mathrm{mg} / \mathrm{ml}$. (A) The retention time of Norharmane was 8.613 minute measured at $254 \mathrm{~nm}$. (B) The retention time of DISS was 13.15 minute measured at $330 \mathrm{~nm}$. (C) The retention time of TMCA was 18.68 minutes measured at $310 \mathrm{~nm}$. (D) The retention time of tenuifolin was 21.38 minute measured at $202 \mathrm{~nm}$.

test. We found that there was no difference in locomotor activity in the open field test between experimental groups. Therefore, our findings more likely reflect RP's action on cognitive functions. Also reduced anxiety can be misinterpreted as a reduced fear memory. Anti-anxiety effects due to RP have been reported [15]. However, the dose of RP administered did not affect anxiety-like behaviors in our results. If the reduction of contextual freezing is due to anxiolytic effects, this reduction should also result in the reduction of cued freezing.

More research is needed on the mechanism by how RP improves spatial learning without affecting cued fear memory and working memory, while reducing contextual fear memory. A previous study has shown that mice with heterozygous knockout of CBP (CREB binding protein), a histone acetyltransferase related with learning and memory [16], exhibited impaired contextual fear memory, but normal cued fear memory and spatial learning [17]. Similarly, mice with dominant-negative CBP mutation showed impaired contextual fear memory and spatial memory, but normal cued fear memory [18]. Mice with heterozygous truncated CBP proteins showed impaired cued fear, but intact contextual fear [19]. PCAF (p300/CBP associated factor) knockout mice showed impaired spatial memory, but enhanced contextual fear [20]. In addition, silencing of GSK-3 $\beta$ (glycogen synthase kinase-3 $\beta$ ) in the dentate gyrus inhibited contextual memory, but not cued fear memory, spatial memory, locomotor activity and anxiety related behaviors [21]. These results indicate that spatial navigation memory, contextual fear memory and cued fear memory are mediated by distinct neuronal substrates.

Because of the specific suppression of contextual fear memory, without compromising spatial reference and working memory, RP can be considered as a candidate for PTSD treatment. Drugs currently in use for PTSD need urgent improvement [22]. The 
response rate of the currently available selective serotonin reuptake inhibitors is about $60 \%$ and the full remission rate is only about $30 \%$. Especially in combat-related PTSD, the effect is very poor [22]. Based on the finding that noradrenergic hyperreactivity could be the basis of fear memory enhancement, administration of $\alpha 1$-antagonists are shown to relieve symptoms associated with sleep disturbances [23]. However, instead of mere symptom relief, new therapies for PTSD require modifications to the cognitive processes associated with fear memory retrieval, reconsolidation, and extinction. RP can be seen as a drug that modifies the cognitive processes of fear memory. In preclinical studies, propranolol ( $\beta$-adrenoceptor antagonist) has been shown to block reconsolidation of fear memory, which may be helpful in a clinical setting [24]. Activation of the cannabinoid type 1 receptor also shows an advantage in inhibiting reconsolidation and facilitating extinction of fear memory [25]. Glucocorticoid treatment reduces PTSD symptoms within one month by affecting reconsolidation [26]. GR antagonists reduce the PTSD symptom severity scale in patients with treatment-resistant PTSD [11]. Treatment with GR antagonist RU40555 prior to SPS training inhibits the formation of fear memory [27]. Another GR antagonist, mifepristone, can also prevent the reconsolidation of cue-conditioned fear [11]. It may also be useful to test in the future if RP can modify the cognitive process of fear memory regulation.

BAG1 is a Hsp70/Hsc70-regulating co-chaperone that regulates the activity of GR [28]. Specifically, BAG1 antagonizes the GRmediated effect by attenuating the assembly of GR and blocking GR-mediated transcription in the nucleus [29]. In a previous study, BAG1 promoted recovery from the deleterious consequences of stress exposure in mice [10]. In a pilot study, we found that RP increased BAG1 expression in the HT22 cell line (data not shown). Based on this finding, we investigated whether RP was able to influence BAG1 expression in the hippocampus. In this study we have shown that RP increased the expression of BAG1 in the hippocampus, which was presumed to be related to the inhibition of fear memory.

Among the known active ingredients of RP, norharmane, DISS and TMCA were confirmed by HPLC analysis, but the presence of tunuifolin in RP was not precisely confirmed. It was found that the content of tenuifolin in the dry weight of RP was only $0.006 \%$ [3]. This is because tenuifolin is present in the glycosylated form, known as polygalasaponins, in the crude extract of RP [30]. It is known that polygalasaponins are metabolized by intestinal bacteria and converted to tenuifolin [31]. Therefore, although tenuifolin is an important component associated with the effect of RP, it is hardly detectable in the RP extract.

In conclusion, oral RP extracts attenuated fear memory retrieval in mice exposed to SPS-CF without affecting locomotion, spatial reference, and working memory tasks. These results highlight the need for further study of RP and its constituent compounds as possible therapeutic interventions for exaggerated fear memory such as PTSD.

\section{ACKNOWLEDGEMENTS}

This work was carried out with the support of "Cooperative Research Program for Agriculture Science and Technology Development (Project No. PJ013314)" Rural Development Administration, Republic of Korea.

\section{REFERENCES}

1. May BH, Lu C, Lu Y, Zhang AL, Xue CC (2013) Chinese herbs for memory disorders: a review and systematic analysis of classical herbal literature. J Acupunct Meridian Stud 6:2-11.

2. Sun XL, Ito H, Masuoka T, Kamei C, Hatano T (2007) Effect of Polygala tenuifolia root extract on scopolamine-induced impairment of rat spatial cognition in an eight-arm radial maze task. Biol Pharm Bull 30:1727-1731.

3. Shin IJ, Son SU, Park H, Kim Y, Park SH, Swanberg K, Shin JY, Ha SK, Cho Y, Bang SY, Lew JH, Cho SH, Maeng S (2014) Preclinical evidence of rapid-onset antidepressant-like effect in Radix Polygalae extract. PLoS One 9:e88617.

4. Kawashima K, Miyako D, Ishino Y, Makino T, Saito K, Kano Y (2004) Anti-stress effects of 3,4,5-trimethoxycinnamic acid, an active constituent of roots of Polygala tenuifolia (Onji). Biol Pharm Bull 27:1317-1319.

5. North CS, Suris AM, Davis M, Smith RP (2009) Toward validation of the diagnosis of posttraumatic stress disorder. Am J Psychiatry 166:34-41.

6. Friedman MJ, Resick PA, Bryant RA, Brewin CR (2011) Considering PTSD for DSM-5. Depress Anxiety 28:750-769.

7. Pratchett LC, Daly K, Bierer LM, Yehuda R (2011) New approaches to combining pharmacotherapy and psychotherapy for posttraumatic stress disorder. Expert Opin Pharmacother 12:2339-2354.

8. Yamamoto S, Morinobu S, Takei S, Fuchikami M, Matsuki A, Yamawaki S, Liberzon I (2009) Single prolonged stress: toward an animal model of posttraumatic stress disorder. Depress Anxiety 26:1110-1117.

9. Wang H, Zuo D, He B, Qiao F, Zhao M, Wu Y (2012) Conditioned fear stress combined with single-prolonged stress: a new PTSD mouse model. Neurosci Res 73:142-152.

10. Maeng S, Hunsberger JG, Pearson B, Yuan P, Wang Y, Wei Y, 
McCammon J, Schloesser RJ, Zhou R, Du J, Chen G, McEwen B, Reed JC, Manji HK (2008) BAG1 plays a critical role in regulating recovery from both manic-like and depression-like behavioral impairments. Proc Natl Acad Sci USA 105:87668771.

11. Golier JA, Caramanica K, Demaria R, Yehuda R (2012) A pilot study of mifepristone in combat-related PTSD. Depress Res Treat 2012:393251.

12. Yang JH, Han SJ, Ryu JH, Jang IS, Kim DH (2009) Ginsenoside Rh2 ameliorates scopolamine-induced learning deficit in mice. Biol Pharm Bull 32:1710-1715.

13. García-Gutiérrez MS, Pérez-Ortiz JM, Gutiérrez-Adán A, Manzanares J (2010) Depression-resistant endophenotype in mice overexpressing cannabinoid CB(2) receptors. Br J Pharmacol 160:1773-1784.

14. Zhang H, Han T, Zhang L, Yu CH, Wan DG, Rahman K, Qin LP, Peng C (2008) Effects of tenuifolin extracted from radix polygalae on learning and memory: a behavioral and biochemical study on aged and amnesic mice. Phytomedicine 15:587-594.

15. Yao Y, Jia M, Wu JG, Zhang H, Sun LN, Chen WS, Rahman K (2010) Anxiolytic and sedative-hypnotic activities of polygalasaponins from Polygala tenuifolia in mice. Pharm Biol 48:801-807.

16. Barrett RM, Wood MA (2008) Beyond transcription factors: the role of chromatin modifying enzymes in regulating transcription required for memory. Learn Mem 15:460-467.

17. Alarcón JM, Malleret G, Touzani K, Vronskaya S, Ishii S, Kandel ER, Barco A (2004) Chromatin acetylation, memory, and LTP are impaired in $\mathrm{CBP}+/-$ mice: a model for the cognitive deficit in Rubinstein-Taybi syndrome and its amelioration. Neuron 42:947-959.

18. Wood MA, Kaplan MP, Park A, Blanchard EJ, Oliveira AM, Lombardi TL, Abel T (2005) Transgenic mice expressing a truncated form of CREB-binding protein (CBP) exhibit deficits in hippocampal synaptic plasticity and memory storage. Learn Mem 12:111-119.

19. Oike Y, Hata A, Mamiya T, Kaname T, Noda Y, Suzuki M, Yasue H, Nabeshima T, Araki K, Yamamura K (1999) Truncated CBP protein leads to classical Rubinstein-Taybi syndrome phenotypes in mice: implications for a dominant-negative mechanism. Hum Mol Genet 8:387-396.

20. Duclot F, Jacquet C, Gongora C, Maurice T (2010) Alteration of working memory but not in anxiety or stress response in p300/CBP associated factor (PCAF) histone acetylase knockout mice bred on a C57BL/6 background. Neurosci Lett
475:179-183.

21. Chew B, Ryu JR, Ng T, Ma D, Dasgupta A, Neo SH, Zhao J, Zhong Z, Bichler Z, Sajikumar S, Goh EL (2015) Lentiviral silencing of GSK-3 $\beta$ in adult dentate gyrus impairs contextual fear memory and synaptic plasticity. Front Behav Neurosci 9:158.

22. Friedman MJ (1997) Drug treatment for PTSD. Answers and questions. Ann NY Acad Sci 821:359-371.

23. Peskind ER, Bonner LT, Hoff DJ, Raskind MA (2003) Prazosin reduces trauma-related nightmares in older men with chronic posttraumatic stress disorder. J Geriatr Psychiatry Neurol 16:165-171.

24. Brunet A, Orr SP, Tremblay J, Robertson K, Nader K, Pitman RK (2008) Effect of post-retrieval propranolol on psychophysiologic responding during subsequent script-driven traumatic imagery in post-traumatic stress disorder. J Psychiatr Res 42:503-506.

25. Pamplona FA, Takahashi RN (2006) WIN 55212-2 impairs contextual fear conditioning through the activation of CB1 cannabinoid receptors. Neurosci Lett 397:88-92.

26. Aerni A, Traber R, Hock C, Roozendaal B, Schelling G, Papassotiropoulos A, Nitsch RM, Schnyder U, de Quervain DJ (2004) Low-dose cortisol for symptoms of posttraumatic stress disorder. Am J Psychiatry 161:1488-1490.

27. Kohda K, Harada K, Kato K, Hoshino A, Motohashi J, Yamaji T, Morinobu S, Matsuoka N, Kato N (2007) Glucocorticoid receptor activation is involved in producing abnormal phenotypes of single-prolonged stress rats: a putative posttraumatic stress disorder model. Neuroscience 148:22-33.

28. Zhou R, Gray NA, Yuan P, Li X, Chen J, Chen G, Damschroder-Williams P, Du J, Zhang L, Manji HK (2005) The antiapoptotic, glucocorticoid receptor cochaperone protein BAG1 is a long-term target for the actions of mood stabilizers. J Neurosci 25:4493-4502.

29. Schneikert J, Hübner S, Martin E, Cato AC (1999) A nuclear action of the eukaryotic cochaperone RAP46 in downregulation of glucocorticoid receptor activity. J Cell Biol 146:929940.

30. Cheng MC, Li CY, Ko HC, Ko FN, Lin YL, Wu TS (2006) Antidepressant principles of the roots of Polygala tenuifolia. J Nat Prod 69:1305-1309.

31. Yabe T, Tuchida H, Kiyohara H, Takeda T, Yamada H (2003) Induction of NGF synthesis in astrocytes by onjisaponins of Polygala tenuifolia, constituents of kampo (Japanese herbal) medicine, Ninjin-yoei-to. Phytomedicine 10:106-114. 